\title{
Sleep and Health in Oil Rig Workers-Before and After a Two Week Work Period Offshore
}

\author{
Siri WAAGE ${ }^{1,2,3 *}$, Ståle PALLESEN ${ }^{2,4}$, Bente Elisabeth MOEN ${ }^{1,5}$ and Bjørn BJORVATN ${ }^{1,2}$ \\ ${ }^{1}$ Department of Public Health and Primary Health Care, University of Bergen, Norway \\ ${ }^{2}$ Norwegian Competence Center for Sleep Disorders, Haukeland University Hospital, Norway \\ ${ }^{3}$ Uni Research, Norway \\ ${ }^{4}$ Department of Psychosocial Science, University of Bergen, Norway \\ ${ }^{5}$ Department of Occupational Medicine, Haukeland University Hospital, Norway
}

Received July 6, 2012 and accepted October 11, 2012

Published online in J-STAGE November 28, 2012

\begin{abstract}
This study compared subjective sleep and subjective health complaints among Norwegian oil rig workers, before and after a two week work period. The study also compared differences between two different work schedules. The workers worked either two weeks of day shift $(n=90)$ or two weeks of a swing shift schedule ( $n=93$ ), involving one week of night shifts, immediately followed by one week of day shifts. Overall, the workers reported significantly poorer sleep quality and more complaints of insomnia at the end compared to the start of the work period. However, there was no significant difference in terms of subjective health complaints. Furthermore, there were no clear differences in changes in sleep quality, insomnia or subjective health complaints during the work period between day- and swing shift workers. However, at the end of the work period a higher proportion of insomniacs were seen among swing shift workers compared with day workers. To conclude, sleep quality and complaints of insomnia became worse during the work period. However, there were few differences in changes in terms of sleep or subjective health complaints between day- and swing shift, suggesting that $12 \mathrm{~h}$ day shift affected sleep and health similarly to the schedule involving night work.
\end{abstract}

Key words: Shift work, Sleep, Health

\section{Introduction}

Shift work and extended work hours are associated with several health and sleep problems ${ }^{1-3)}$. Among others, fatigue, gastrointestinal complaints, musculoskeletal complaints, cardiovascular disease and breast cancer are all reported to be more common in people who work shifts compared to people who only work during the day ${ }^{2,4-8)}$.

*To whom correspondence should be addressed.

E-mail: siri.waage@isf.uib.no

(C)2013 National Institute of Occupational Safety and Health
Shift workers commonly report more sleep disturbances than day workers ${ }^{4}$. The most frequently reported sleep complaints related to shift work are insomnia, reduced sleep duration and sleepiness during work ${ }^{1)}$. Following night work, the sleep schedule is displaced and the preferred sleep-wake cycle becomes misaligned with the endogenous circadian pacemaker, which typically lead to reduced sleep duration ${ }^{8,9)}$. It is assumed that the conflict between work hours and biological rhythms may cause health problems ${ }^{10)}$.

Extended work hours can be defined as working more than $48 \mathrm{~h}$ a week ${ }^{11)}$. Extended or long work hours have 
been associated with objective and self-rated health problems, sickness absence and fatigue ${ }^{3)}$, but the evidence is not strong ${ }^{12)}$ as some studies have not shown such associations ${ }^{13)}$. Working more than $50 \mathrm{~h}$ per week have been found to be related to reduced sleep duration, albeit not to insomnia $^{14,15)}$.

The offshore oil industry has a $24 / 7$ production with all workers living on sea based platforms during their work period, and shift work is an essential part of many offshore jobs ${ }^{16)}$. In Norway, most offshore personnel follow a work schedule that consists of two weeks of work, followed by four weeks off work at home. During the work period offshore different work schedules are used, but the most common are $12 \mathrm{~h}$ day shift for two weeks, $12 \mathrm{~h}$ night shift for two weeks or a swing shift schedule that consists of one week of night work immediately followed by one week of day shift. Many offshore workers prefer the swing shift because they start their four weeks free period at home more or less adjusted to a normal daynight rhythm ${ }^{16,17)}$.

As outlined above, many offshore oil rig workers work nights, and normally all offshore oil rig workers work extended work hours ( $84 \mathrm{~h}$ work week). The purpose of the present study was to examine Norwegian oil rig workers and to compare the workers' sleep quality, insomnia symptoms and subjective health after a four week free period at home with the workers' sleep quality, insomnia symptoms and subjective health following a two week work period at the oil rig. We hypothesized that the two week work period at the oil rig with $12 \mathrm{~h}$ shifts would lead to poorer sleep and health, and that swing shift workers would report sleep and health to be more impaired compared to day workers.

\section{Subjects and Methods}

\section{Design and procedure}

The study was performed among Norwegian oil rig workers working in the North Sea. The workers' sleep and health were investigated at the beginning of a two-week work period at the oil rig (after a four week free period at home), and compared with the workers' sleep and health at the end of the two week work period. A total of 259 workers were invited to participate in the study. 188 workers (178 men and 5 women) agreed to participate, yielding a response rate of $72.6 \%$. Five workers were excluded from the analyses due to missing data. The same questionnaires were completed during the first (reflecting the four-week free period) and last workday (reflecting the two-week work period) at the oil rig, and were handed out and collected by the nursing staff. Ninety of the workers worked $14 \mathrm{~d}$ of $12 \mathrm{~h}$ day shifts $(0700 \mathrm{~h}-1900 \mathrm{~h})$, and 93 of the workers worked a swing shift schedule, implying one week of $12 \mathrm{~h}$ night shifts (1900h-0700h) followed immediately by one week of $12 \mathrm{~h}$ day shifts. On the "swing" day, the night shift ended at $0400 \mathrm{~h}$ with a $6 \mathrm{~h}$ break before the day shift began at $1000 \mathrm{~h}$ and lasted to $1900 \mathrm{~h}$. The length of both day shift and night shift was equal and nearly all workers $(97.5 \%)$ worked either with production or drilling, indicating comparable work load, as the oil rig runs a $24 \mathrm{~h}$ production. Drilling operation and production work differ regarding tasks, but both types of work are performed in the same area of the platforms, with similarities in physical work load and noise exposure ${ }^{18)}$. Chemical exposure may differ slightly comparing drillers and production workers, but exposure levels for hydrocarbons are in general low, and exposure to neurotoxins is rare ${ }^{19)}$. All workers slept in single cabins in the same area of the oil rig, with similar lightening conditions. Noise levels were low in the cabins for all workers on the rig.

\section{Questionnaires}

Validated questionnaires were used as outcome measures; Sleep was measured by the Pittsburgh Sleep Quality Index (PSQI) ${ }^{20)}$, and insomnia symptoms were assessed by the Bergen Insomnia Scale (BIS) ${ }^{21)}$. Subjective health complaints were measured by the Subjective Health Complaints Inventory (SHC) ${ }^{22}$. PSQI consists of 19 self-rated questions about sleep experienced the last month, yielding seven components: subjective sleep quality, sleep latency, sleep duration, sleep efficiency, sleep disturbance, use of sleep medications and daytime dysfunction. Each component is scored from 0 to 3, yielding a global PSQI score between 0 and 21. A PSQI global score greater than 5 is used as an indicator of sleep problems, and differentiates between subjects who have sleep of good quality from those with poor quality ${ }^{20)}$. The PSQI is validated in Norwegian with satisfactory validity and reliability ${ }^{23)}$. The Cronbach alpha for the PSQI in the present study was 0.70 . BIS consists of six items and is based on the diagnostic criteria for insomnia stated in the Diagnostic and Statistical Manual for Mental Disorders (DSM-IV, American Psychiatric Association, 2000). During the last month, how many days per week (0-7): 1) Did you spend more than 30 min to fall asleep after turning out the lights? 2) Did you wake up for more than 30 min during sleep? 3) Did you wake up more than $30 \mathrm{~min}$ earlier than you wanted, without being able to fall asleep 
again? 4) Have you not felt adequately rested following sleep? 5) Have you been so sleepy/tired that it has interfered with school/job or your private life? 6) Have you been dissatisfied with your sleep? The scale yields a continuous score ranging from 0 to 42 , which is calculated by adding the score of each of the six items. Higher values indicate a greater degree of insomnia symptoms ${ }^{21)}$. Respondents were categorized as insomniacs if they scored 3 or more on at least one of items $1-4$, and 3 or more on at least one of items 5 and 6 . The time frame for BIS in the present study adhered to the last four weeks when administered the first day at the oil rig and symptoms during the last two weeks when administered at the end of the work period. In the present study, Cronbach alpha for the BIS was 0.83. SHC consists of 29 items measuring subjective somatic and psychological complaints experienced within the last 30 days. The instrument has five subscales: Musculoskeletal pain ( 8 items: headache, neck pain, upper back pain, low back pain, arm pain, shoulder pain, migraine and leg pain), "pseudoneurological" complaints (7 items: palpitation, heat flushes, sleep problems, tiredness, dizziness, anxiety and depression), gastrointestinal complaints (7 items: heartburn, stomach discomfort, ulcer/non-ulcer dyspepsia, stomach pain, gas discomfort, diarrhoea and constipation), allergy (5 items: asthma, breathing difficulties, eczema, allergy, chest pain) and flu (2 items: colds/flu, cough). Severity of each complaint is rated on a 4-point scale $(0=$ no complaints, $1=$ some, $2=$ much, $3=$ severe complaints). Each complaint is also scored for duration (number of days) during the last 30 days. Severity multiplied by days of duration has been used to obtain a total score indicating the degree of health complaints. The questionnaire has satisfactory validity and reliability ${ }^{24)}$. The SHC had a Cronbach's alpha of 0.81 in the present study.

We also asked for background data such as sex, age, marital status, years worked offshore, present smoking (yes/no) and self-rated physical health; "How would you describe our own health?", rated on a five point scale from very poor to very good.

\section{Ethics}

The study was approved by the Regional Ethics Committee of Western Norway (REK-West) and by the Norwegian Social Data Service (NSD). The participants were informed that no information from the questionnaires would be given to the company, and that the company only would get access to anonymous results as presented in this publication. The workers returned their questionnaires together with their written consent to participate in the study in a sealed envelope to the medical nurse at the oil rig before they were sent to the researchers at the University of Bergen.

\section{Statistical analyses}

PASW Statistics 18 for Windows was used for the statistical analyses. For comparisons between the workers' sleep and subjective health at the beginning of the two week work period and the workers' sleep and health at the end of the two week work period, paired samples $t$-test and effect sizes (Cohen's d for paired values) was calculated. A $2 \times 2$ ANOVA with one between groups factor (day shift vs. swing shift) and with one within subjects factor (before vs. at the end of the two week work period) was used to compare the two work schedules. Demographics as well as scores on the instruments before the work period were compared among workers in different schedules using unpaired $t$-tests and Pearson chi-square tests. Significance level was set at 0.05 .

\section{Results}

The mean age of the workers was $42.9 \mathrm{yr}$ (SD 10.6), ranging from 19-62 yr. The mean years with offshore work was 16.2 (SD 8.9), ranging from 0.5 to $37 \mathrm{yr} .78 .1 \%$ of the workers were married or cohabiting. $23.0 \%$ of the workers were smokers and $81.5 \%$ reported their health as good or very good. There were significant differences between the day workers and swing shift workers in terms of age, years with offshore work and self-rated physical health, but not on any of the outcome measures at the start of the two week work period (sleep quality, insomnia or subjective health) (Table 1).

The oil rig workers reported significantly poorer sleep (measured by the PSQI) and more complaints of insomnia (measured by the BIS) at the end of the two week work period compared to the start of the two week work period (Table 2). However, there was no significant difference in subjective health complaints (measured by the SHC) from the start to the end of the two week work period (Table 2). The day workers reported significantly poorer sleep (measured by the PSQI) from the start to the end of the work period, but less subjective health complaints (Table 3). The swing shift workers reported poorer sleep (measured by the PSQI) and more complaints of insomnia (measured by the BIS) at the end of the two week work period compared to the start of the work period (Table 3). When comparing the two shift work schedules, there were no clear significant difference in changes (insignificant interaction 
Table 1. Demographic, health and sleep variables in day workers and swing shift workers before the two week work period

\begin{tabular}{lccc}
\hline & $\begin{array}{c}\text { Day workers } \\
(\mathrm{n}=90)\end{array}$ & $\begin{array}{c}\text { Swing shift workers } \\
(\mathrm{n}=93)\end{array}$ & $p$-value \\
\hline Age, mean years (SD) & $46.2(10.0)$ & $39.8(10.2)$ & $<0.001^{\mathrm{a}}$ \\
Years with offshore work, mean (SD) & $18.2(8.2)$ & $14.2(9.0)$ & $0.002^{\mathrm{a}}$ \\
Marital status (\% married/cohabiting) & $83.3 \%$ & $73.1 \%$ & $0.12^{\mathrm{b}}$ \\
Daily smokers in \% & $23.3 \%$ & $22.6 \%$ & $0.65^{\mathrm{b}}$ \\
Self-rated health as good/very good & $73.4 \%$ & $89.3 \%$ & $0.02^{\mathrm{b}}$ \\
PSQI - mean (SD) & $4.6(2.2)$ & $4.5(2.8)$ & $0.75^{\mathrm{a}}$ \\
\% of workers with PSQI > 5 & $27.8 \%$ & $26.9 \%$ & $0.96^{\mathrm{b}}$ \\
BIS - mean (SD) & $7.8(6.0)$ & $7.2(6.8)$ & $0.54^{\mathrm{a}}$ \\
\% of Insomniacs & $15.6 \%$ & $16.1 \%$ & $0.92^{\mathrm{b}}$ \\
SHC - mean (SD) & $6.8(4.5)$ & $7.6(7.4)$ & $0.34^{\mathrm{a}}$ \\
\hline
\end{tabular}

${ }^{\mathrm{a}} p$-values are based on unpaired $t$-tests. ${ }^{\mathrm{b}} p$-values are based on Pearson $\chi^{2}$ tests.

PSQI=Pittsburgh Sleep Quality Index, BIS=Bergen Insomnia Scale, SHC=Subjective Health Complaints.

Table 2. Changes in sleep quality, insomnia and subjective health complaints, comparisons of the start and the end of a two week work period offshore in all workers

\begin{tabular}{lccc}
\hline & $\begin{array}{c}\text { Start of the two week work period } \\
\text { Mean (SD) }\end{array}$ & $\begin{array}{c}\text { End of the two week work period } \\
\text { Mean (SD) }\end{array}$ & $p$-value* \\
\hline PSQI (n=158) & $4.5(2.6)$ & $5.7(2.7)$ & $p<0.0005$ \\
BIS (n=163) & $7.5(6.4)$ & $12.5(12.9)$ & $p<0.0005$ \\
SHC $(\mathrm{n}=181)$ & $7.2(6.2)$ & $6.7(5.9)$ & $p=0.12$ \\
\hline
\end{tabular}

PSQI=Pittsburgh Sleep Quality Index, BIS=Bergen Insomnia Scale, SHC=Subjective Health Complaints, *Paired Samples $t$-test.

Table 3. Comparisons of sleep quality, insomnia and subjective health complaints between day shift and swing shift workers during a two week work period offshore

\begin{tabular}{|c|c|c|c|c|c|c|c|c|}
\hline & \multicolumn{3}{|c|}{ Day workers } & \multicolumn{3}{|c|}{ Swing shift workers } & \multicolumn{2}{|c|}{$\begin{array}{c}\text { Interaction } \\
\text { (ShiftxTime) }^{\mathrm{c}}\end{array}$} \\
\hline & $\begin{array}{l}\text { Mean (SD) } \\
\text { Start - End }\end{array}$ & $p$-value ${ }^{a}$ & $\begin{array}{l}\text { Effect } \\
\text { size }^{\text {b }}\end{array}$ & $\begin{array}{l}\text { Mean (SD) } \\
\text { Start - End }\end{array}$ & $p$-value $^{\mathrm{a}}$ & $\begin{array}{l}\text { Effect } \\
\text { size }^{\text {b }}\end{array}$ & F-value & $p$-value \\
\hline PSQI ( $\mathrm{n}=158)$ & $\begin{array}{c}4.6(2.2)-5.4(2.5) \\
(\mathrm{n}=80)\end{array}$ & $<0.0005$ & 0.34 & $\begin{array}{c}4.5(2.9)-5.9(2.8) \\
(\mathrm{n}=78)\end{array}$ & $<0.0005$ & 0.50 & 3.1 & 0.08 \\
\hline BIS (n=163) & $\begin{array}{c}7.9(5.9)-11.2(15.6) \\
(\mathrm{n}=80)\end{array}$ & 0.06 & 0.28 & $\begin{array}{c}7.1(6.8)-13.8(9.6) \\
(\mathrm{n}=83)\end{array}$ & $<0.0005$ & 0.80 & 2.72 & 0.10 \\
\hline SHC $(n=181)$ & $\begin{array}{c}6.7(4.6)-5.8(4.4) \\
(\mathrm{n}=89)\end{array}$ & 0.002 & -0.22 & $\begin{array}{c}7.6(7.4)-7.6(7.0) \\
(\mathrm{n}=92)\end{array}$ & 0.96 & 0.00 & 2.25 & 0.14 \\
\hline
\end{tabular}

${ }^{a}$ Paired-Samples $t$-test, comparing values before and after a two-week work period. ${ }^{b}$ Effect size (Cohens d) for paired values. ${ }^{\mathrm{c}}$ Mixed between-within subjects analysis of variance comparing the two work schedules, Effect sizes (Cohens d) concern group differences at the end of the work period. PSQI=Pittsburgh Sleep Quality Index, BIS=Bergen Insomnia Scale, SHC=Subjective Health Complaints .

effects) during the two week work period in sleep quality, insomnia or subjective health complaints between the day shift and swing shift workers (Table 3).

At the start of the work period, $27.8 \%(n=25)$ of the day workers reported a PSQI score above 5 as compared with $26.9 \%(\mathrm{n}=25)$ of the swing shift workers $(p=0.96)$. Similarly, $15.6 \%(\mathrm{n}=14)$ of the day workers were categorized as insomniacs as compared with $16.1 \%(n=15)$ of the swing shift workers $(p=0.92)$. At the end of the two week work period, $33.3 \%(n=30)$ of the day workers reported a 
PSQI score above 5 as compared with $44.1 \%(n=41)$ of the swing shift workers $(p=0.09)$. At the end of the two week work period offshore, there were significantly more swing shift workers categorized as insomniacs compared to day workers $(39.8 \%, \mathrm{n}=22$ vs. $24.4 \%, \mathrm{n}=37$ respectively, $p=0.03$ ).

\section{Discussion}

For day shift- and swing shift workers sleep quality became poorer and complaints of insomnia increased during a two week work period at the oil rig. There was no clear difference in this increase in complaints between the day workers and the swing shift workers. However, at the end of the two week work period significantly more of the swing shift workers were categorized as insomniacs compared with the day workers. The subjective health complaints of the oil rig workers did not increase during a two week work period offshore, and there was no difference when comparing the two shift work schedules. In fact, subjective health complaints were reduced during the work period among the day shift workers.

The oil rig workers reported poorer sleep quality as measured by the PSQI and more insomnia measured by the BIS at the end of the two week work period offshore, supporting parts of our first hypothesis, suggesting that $12 \mathrm{~h}$ work shifts would lead to poorer sleep. Studies from the offshore oil industry have found that night workers report better sleep that their onshore counterparts ${ }^{25}$. Also, a quicker adjustment to night work is reported in offshore oil rig workers compared to what is found in other shift working populations ${ }^{26,27)}$. Still, in the study by Parkes ${ }^{25)}$, a significant higher proportion of offshore workers (54\%) report sleep problems compared to onshore workers (36\%). This is in line with another study among 179 Brazilian offshore workers, the shift- and night workers in this study reported more sleep problems in terms of reduced sleep quality, increased sleep latency, frequent disturbance and tiredness when awake compared with fixed $12 \mathrm{~h}$ day work$\operatorname{ers}^{28)}$.

The results from the present study may be interpreted as a support for the fact that during a two week work period offshore, sleep is more affected by shift work than subjective health. In that respect, sleep problems may be regarded as a more acute effect of shift work experienced from day to day, as compared to poor self-reported health which can be implied as a long-term effect, and that such complaints will be manifested after longer exposure time. Shift workers are reported to have increased health risks compared to the general population using more objective health measures such as for instance various biological measures, BMI or blood pressure ${ }^{29,30)}$. It has been argued that offshore operators tend to report fewer minor health complaints than their onshore counterparts ${ }^{31)}$, more in line with the present study, where no significant changes in subjective health complaints between the start and the end of the two-week work period were found. Among the swing shift workers there was no significant difference in subjective health complaints during the two week work period, and the day shift workers even reported significantly less subjective health complaints at the end of the work period compared to at the start of the work period offshore. When offshore, Norwegian oil rig workers have $12 \mathrm{~h}$ of work between each work shift. During these $12 \mathrm{~h}$, the workers have no social obligations, but they eat, rest, exercise, and social interact in addition to ensure enough sleep. Viewed in this light, one may presume that the time available for sleep is shorter than when onshore. On the other hand, since the offshore workers have no social obligations, the $12 \mathrm{~h}$ between each shift are considered to be more than sufficient to recover and to obtain adequate amount of rest and sleep. In addition, the offshore workers have four weeks off work between the two-weeks working periods at the oil rig. No domestic demands offshore and sufficient time to recover between each shift and also between each work period may be contributing factors of why the workers seem to deal with shift work and with the long work hours in terms of reporting small changes in subjective health. These findings are in accordance with other studies where long and special work hours have not been found to be associated with adverse health effects. Male tunnel workers working $10 \mathrm{~h}$ work shifts for 21 consecutive days or nights did not report a change in the prevalence of subjective health complaints during an observation period of eight months ${ }^{32)}$ and male mine workers working $10 \mathrm{~h}$ work shift of $14 \mathrm{~d}$ on and $14 \mathrm{~d}$ off did not report any change in subjective health complaints in a two year follow-up study ${ }^{33)}$. Similarly, in a study of construction workers working $84 \mathrm{~h}$ a week with alternate weeks off, the workers did not report higher prevalence of subjective health complaints compared to workers working $40 \mathrm{~h}$ a week ${ }^{34)}$.

Based on knowledge about the circadian timing system and the fact that day time sleep is out of phase with the diurnal rhythm, resulting in reduced sleep duration, more awakenings, sleepiness during the wake period and reduced performance ${ }^{1)}$, our second hypothesis was that the impairment in sleep and health during the two week 
work period would be worse for the swing shift workers compared to the day workers. In line with this, a review of literature on offshore personnel claimed that shift patterns involving rotation comparable with the swing shift schedule used in the present study will result in a poorer profile on health related measures compared to day work ${ }^{31)}$. The workers in our study reported poorer sleep quality at the end of the two week work period as compared with the start of the work period, but there were surprisingly few differences between the two work schedules in contrast to what we had hypothesized. At the end of the work period there was however a trend showing a difference in sleep quality between the day workers and the swing shift workers. The groups were similar at the start of the work period, whereas at the end of the work period $44.1 \%$ of the swing shift workers scored above cut off on the PSQI as compared to $33.3 \%$ of the day workers. In addition, there was a significant difference between the two work schedules at the end of the two-week work period concerning the prevalence of insomnia, supporting our second hypothesis that swing shift work lead to more sleep problems than day work. The reported insomnia is most likely to be associated with the swinging from night to day work. Previous studies on swing shift work from the Norwegian offshore industry have shown that swing shift workers report large variations in re-adaptation back to a day-night rhythm after night shift work, and also shorter sleep duration and more sleepiness in the middle of the work period when working swing shift ${ }^{26,35,36)}$. Both the day workers and the swing shift workers worked long work shifts comprising $12 \mathrm{~h} / 84 \mathrm{~h}$ per week during the work period. Our results may suggest that poor sleep is mostly related to long work hours ( $84 \mathrm{~h}$ per week) or possibly related to early morning start times $(07.00 \mathrm{~h})$, and not necessarily only to shift work itself, as we hypothesized.

The present study has some strengths as well as some limitations to be considered. Field studies on an offshore oil rig environment can be regarded as similar to laboratory studies, with high control with confounding factors. All workers in the present study were working and living under similar conditions, without interfering factors such as domestic and social demands, providing good control over eating, sleeping and social habits. A limitation of the present study is that all data are self-reported. Objective measures of sleep and health would have strengthened the findings. On the other hand, the questionnaires used in the present study are well validated and commonly used in shift work research, and the results are therefore easy to compare to other similar studies. However, it is a weak- ness that both the PSQI and the SHC questionnaires are reflecting 30 days in retrospect, meaning that the workers may report both from the two weeks offshore and from the weeks at home prior to this work period. However, we assume that any changes in the scores most likely could be related to the two week work period. Furthermore, our results are limited to a relatively small sample size, predominantly males working in a controlled and confined shift work environment. This limits the generalization of the results to other working conditions and shift work populations. A selection bias is likely to be present in this group of workers, as a health certificate is required for work offshore $^{18)}$. In addition to self-selection to shift work initially, some shift workers are likely to leave shift work within a few years, leaving a group of healthy shift workers ${ }^{37}$. This is supported by the fact that before the work period, the workers in the present study reported lower PSQI scores, BIS scores and subjective health complaints scores than what is reported in other Norwegian populations ${ }^{21,23,24)}$. As the group of day workers were both older and with longer experience with offshore work, it is likely that many of the day workers had previous shift work experience, and that one reason for changing to day work could be problems with tolerance to shift work. However, there were no differences in sleep quality, insomnia or subjective health problems between the two shift work groups at the start of the work period, indicating no specific selection into any of these two groups. After the work period the workers reported similar PSQI scores as the Norwegian norms ${ }^{23)}$, but lower scores on the $\mathrm{SHC}^{24)}$. However, the insomnia scores after the two week work period were higher than what is reported in other Norwegian populations ${ }^{21)}$, indicating that long work hours during offshore work may lead to insomnia symptoms.

In conclusion, oil rig workers reported poorer sleep quality and more complaints of insomnia at the end of a two week work period offshore. More swing shift workers reported insomnia at the end of the work period compared with day shift workers, but otherwise there were only few differences in sleep and health between the two different work schedules. This suggests that the reported sleep problems were related to offshore work and /or long work hours, and that not only night work affects sleep.

\section{Acknowledgement}

The authors would like to thank the oil company BP Norway and all the workers at the oil rig for their collaboration. 


\section{References}

1) Åkerstedt T (2003) Shift work and disturbed sleep/ wakefulness. Occup Med (Lond) 53, 89-94. [Medline] [CrossRef]

2) Costa G (2003) Shift work and occupational medicine: an overview. Occup Med (Lond) 53, 83-8. [Medline] [CrossRef]

3) Härmä M (2006) Workhours in relation to work stress, recovery and health. Scand J Work Environ Health 32, 502-14. [Medline] [CrossRef]

4) Åkerstedt T (1998) Shift work and disturbed sleep/ wakefulness. Sleep Med Rev 2, 117-28. [Medline] [CrossRef]

5) Costa G (2010) Shift work and health: current problems and Preventive Actions. Saf Health Work 1, 112-23. [Medline] [CrossRef]

6) Knutsson A, Boggild H (2010) Gastrointestinal disorders among shift workers. Scand J Work Environ Health 36, 85-95. [Medline] [CrossRef]

7) Sallinen M, Kecklund G (2010) Shift work, sleep, and sleepiness-differences between shift schedules and systems. Scand J Work Environ Health 36, 121-33. [Medline] [CrossRef]

8) Smith CS, Robie C, Folkard S, Barton J, Macdonald I, Smith L, Spelten E, Totterdell P, Costa G (1999) A process model of shiftwork and health. J Occup Health Psychol 4, 207-18. [Medline] [CrossRef]

9) Ursin R, Bjorvatn B, Holsten F (2005) Sleep duration, subjective sleep need, and sleep habits of 40- to 45-yearolds in the Hordaland Health Study. Sleep 28, 1260-9. [Medline]

10) Arendt J (2010) Shift work: coping with the biological clock. Occup Med (Lond) 60, 10-20. [Medline] [CrossRef]

11) Harrington JM (2001) Health effects of shift work and extended hours of work. Occup Environ Med 58, 68-72. [CrossRef]

12) van der Hulst HM (2003) Long workhours and health. Scand J Work Environ Health 29, 171-88. [Medline] [CrossRef]

13) Malt UF, Malt A, Blomhoff S, Refnin I (2002) Functional somatic diseases - a review. Tidsskr Nor Laegeforen 122, 1379-84. [Medline]

14) Åkerstedt T, Fredlund P, Gillberg M, Jansson B (2002) Work load and work hours in relation to disturbed sleep and fatigue in a large representative sample. J Psychosom Res 53, 585-8. [Medline] [CrossRef]

15) Härmä M (2003) Are long workhours a health risk? Scand J Work Environ Health 29, 167-9. [Medline] [CrossRef]

16) Ross JK (2009) Offshore industry shift work-health and social considerations. Occup Med (Lond) 59, 310-5. [Medline] [CrossRef]

17) Harris A, Waage S, Ursin H, Hansen AM, Bjorvatn B, Eriksen HR (2010) Cortisol, reaction time test and health among offshore shift workers. Psychoneuroendocrinology
35, 1339-47. [Medline] [CrossRef]

18) Horneland AM, Moen BE, Holte KA, Merkus SL, Ellingsen KL, Carter T, Aas RW, Ulven A (2011) Loss of health certificates among offshore petroleum workers on the Norwegian Continental Shelf 2002-2010. Int Marit Health 62, 266-75. [Medline]

19) Moen BE, Steinsvåg K, Bråveit M (2004) What do we know about chemical hazards in offshore work? Tidsskr Nor Laegeforen 124, 2627-9. [Medline]

20) Buysse DJ, Reynolds CF, Monk TH, Berman SR, Kupfer DJ (1989) The Pittsburgh Sleep Quality Index: a new instrument for psychiatric practice and research. Psychiatry Res 28, 193-213. [Medline] [CrossRef]

21) Pallesen S, Bjorvatn B, Nordhus IH, Sivertsen B, Hjørnevik M, Morin CM (2008) A new scale for measuring insomnia: the Bergen Insomnia Scale. Percept Mot Skills 107, 691-706. [Medline]

22) Eriksen HR, Ihlebaek C (2002) Subjective health complaints. Scand J Psychol 43, 101-3. [Medline] [CrossRef]

23) Pallesen S, Nordhus IH, Omvik S, Sivertsen B, Matthiesen SB, Bjorvatn B (2005) Pittsburg Sleep Quality Index (PSQI). Tidsskr Nor Laegeforen 42, 714-7.

24) Ihlebaek C, Eriksen HR, Ursin H (2002) Prevalence of subjective health complaints (SHC) in Norway. Scand J Public Health 30, 20-9. [Medline] [CrossRef]

25) Parkes KR (1994) Sleep patterns, shiftwork, and individual differences: a comparison of onshore and offshore controlroom operators. Ergonomics 37, 827-44. [Medline] [CrossRef]

26) Bjorvatn B, Kecklund G, Åkerstedt T (1998) Rapid adaptation to night work at an oil platform, but slow readaptation after returning home. J Occup Environ Med 40, 601-8. [Medline] [CrossRef]

27) Bjorvatn B, Stangenes K, Øyane N, Forberg K, Lowden A, Holsten F, Åkerstedt T (2006) Subjective and objective measures of adaptation and readaptation to night work on an oil rig in the North Sea. Sleep 29, 821-9. [Medline]

28) Menezes MC, Pires ML, Benedito-Silva AA, Tufik S (2004) Sleep parameters among offshore workers: an initial assessment in the Campos Basin, Rio De Janeiro, Brazil. Chronobiol Int 21, 889-97. [Medline] [CrossRef]

29) Knutsson A, Hallquist J, Reuterwall C, Theorell T, Åkerstedt T (1999) Shiftwork and myocardial infarction: a case-control study. Occup Environ Med 56, 46-50. [Medline] [CrossRef]

30) Rajaratnam SM, Arendt J (2001) Health in a 24-h society. Lancet 358, 999-1005. [Medline] [CrossRef]

31) Parkes KR (1998) Psychosocial aspects of stress, health and safety on North Sea installations. Scand J Work Environ Health 24, 321-33. [Medline] [CrossRef]

32) Waage S, Odeen M, Bjorvatn B, Eriksen HR, Ursin H, Hollund BE, Moen BE (2010) Still healthy after extended work hours? Ten hours shift, twenty-one days working period for tunnel workers. Ind Health 48, 804-10. [Medline] 
[CrossRef]

33) Hanoa R, Baste V, Kooij K, Sommervold L, Moen BE (2011) No difference in self reported health among coalminers in two different shift schedules at Spitsbergen, Norway, a two years follow-up. Ind Health 49, 652-7. [Medline] [CrossRef]

34) Persson R, Ørbaek P, Kecklund G, Åkerstedt T (2006) Impact of an 84-hour workweek on biomarkers for stress, metabolic processes and diurnal rhythm. Scand J Work Environ Health 32, 349-58. [Medline] [CrossRef]

35) Saksvik IB, Bjorvatn B, Harvey AG, Waage S, Harris A,
Pallesen S (2011) Adaptation and readaptation to different shift work schedules measured with sleep diary and actigraphy. J Occup Health Psychol 16, 331-44. [Medline] [CrossRef]

36) Waage S, Harris A, Pallesen S, Saksvik IB, Moen BE, Bjorvatn B (2012) Subjective and objective sleepiness among oil rig workers during three different shift schedules. Sleep Med 13, 64-72. [Medline] [CrossRef]

37) Knutsson A, Åkerstedt T (1992) The Healthy-Worker Effect-Self-Selection Among Swedish Shift Workers. Work Stress 6, 163-7. [CrossRef] 